\title{
Fail-Safe Mechanism Problem
}

National Cancer Institute

\section{Source}

National Cancer Institute. Fail-Safe Mechanism Problem. NCI Thesaurus. Code C62997.

Problem associated with the feature that prevents the unsafe use of the device. 